\title{
The Role of Technology in Shaping the Professional Future of Community Pharmacists: The Case of the Electronic Prescription Service in the English National Health Service
}

\author{
Dimitra Petrakaki ${ }^{1}$, Tony Cornford ${ }^{1}$, Ralph Hibberd ${ }^{2}$, \\ Valentina Lichtner ${ }^{1}$, and Nick Barber ${ }^{1}$ \\ ${ }^{1}$ Information Systems and Innovation Group, Department of Management, \\ London School of Economics and Political Science \\ ${ }^{2}$ Department of Practice and Policy, The School of Pharmacy, University of London
}

\begin{abstract}
Information and communication technology (ICT) has been extensively proposed in the last decade as a means to reform, modernize, and reshape national health systems around the globe. In so doing, it inevitably changes work practices, and may have longer term consequences for health care professions. This paper considers how ICT may shape the professional future of community pharmacists by drawing on ongoing research into a national project in England to establish the electronic transmission of prescriptions between doctors and pharmacies. The project illustrates how technology opens up various possibilities that may influence pharmacists' professional standing in the future by shaping their work practices, jurisdictions, roles, values, power, and boundaries. Our aim is not to evaluate these subtle and contradictory changes but to develop an appropriate analytical framework, and to contribute to the debate concerning the role of technology in shaping professional futures.
\end{abstract}

Keywords: Professionals, technology, community pharmacy, electronic prescriptions.

\section{Introduction}

The future is already here-it is just unevenly distributed. (attributed to William Gibson)

Information and communication technology (ICT) has in the last decade been extensively proposed as a means to reform, modernize, and even reshape national health systems. Introduction of ICT based systems is expected to achieve cost effectiveness, support clinical decision making, improve patients' privacy and safety, speed-up delivery, and improve the quality of healthcare (Bates and Gawade 2003; Berg 1997; Chiasson and Davidson 2004). Introducing ICT systems is not without consequences; they challenge health professionals' work practices and roles, the types of knowledge they use, and the modes of collaboration they employ (Aarts et al. 2007). The focus of this paper is on the possibilities that ICT opens up for reshaping 
the work and profession of community pharmacists. Community pharmacists serve the public in high street shops, supermarkets, and some medical centers. They constitute the largest subgroup within the overall pharmacy profession, which includes hospital pharmacists who provide clinical advice to hospitals and healthcare professionals and those who work in pharmaceutical research. From now on reference, to pharmacy(-ists) will imply community pharmacy(-ists).

Our account here is a possible projection of professionalism in the future that is created from research interviews and by an amalgamation of people's recollections of the past, experiences from the present, and expectations for the future. The motivation for the paper is found in the introduction of the electronic prescription service (EPS) into primary care in the English National Health Service. This is a national program to allow doctors to send electronic prescriptions to community pharmacists, and for pharmacists subsequently to send them on for reimbursement by the NHS ${ }^{1}$. This requires a sound infrastructure, networks, software, databases, and new operating procedures, indicating the increased role of ICT in mediating for the generation, transmission, and receipt of prescriptions between doctors and community pharmacists, as well as in serving the processes of reimbursement. We are interested here in exploring the role of this new technical intervention in shaping pharmacists' work practices and profession. To do so, we draw upon a part of our current research evaluating EPS. ${ }^{2}$ We develop two arguments in this paper. First, we propose that EPS can shape six aspects of pharmacists' work: work practices, values, roles, jurisdictions, power, and professional boundaries. Second, we see the consequences of this technology for the pharmacy profession are multiple and often contradictory; on some occasions, technology strengthens and expands pharmacists' professional standing by fostering their values and expanding their jurisdictions, opening up opportunities for re-professionalization. On other occasions, technology challenges pharmacists' role, power, and professional boundaries by allowing new business models and logic to emerge, conditioning in that way possible deprofessionalization. We propose a framework that depicts how and in what ways ICT might shape professional futures.

The paper is structured as follows. Section 2 presents our theoretical framework, drawing upon the sociology of professionals, critical studies on technology, and secondary studies on pharmacists' profession. Section 3 describes our research methodology. Section 4 provides an account of our research into EPS, which is followed by a discussion. The paper ends with some concluding remarks.

\section{Theoretical Framework}

\subsection{Conceptualizing Professionalism}

Professions constitute a "homogeneous group of occupations sharing a unique character and destiny" (Johnson 1993). Professionals are typically organized into associations, which are established in order to promote and protect their interests and rights (Abbott 1988). Professional associations define the skills needed in order to

\footnotetext{
${ }^{1}$ See http://www.connectingforhealth.nhs.uk/systemsandservices/eps.

${ }^{2}$ See http://www.epsevaluation.org.uk/.
} 
become a legitimate member, establish career patterns, and set up mechanisms that regulate entrance and operation in their profession (Abbott 1988; Clarke and Newman 1997; Perkin 2002; Timmermans and Berg 2003). Implicit in this is the establishment of norms, values, and standards of occupational behavior, what is understood as professional conduct (Adamcik et al. 1986). The process of establishing a profession (professionalization) is, therefore, a boundary-making process that binds professionals under a specific regime of work (Adamcik et al. 1986; Kirkpatrick and Ackroyd 2003). Professionalization is both a process of enactment, in as far as it depends on individuals acting their assigned roles as professionals, and a process of subjectification during which individuals are "made-up" as professionals (Hodgson 2005).

For Abbott (1988), the most distinctive characteristic of professionals is the "abstractification" of their knowledge which distinguishes professionals' claims from those of ordinary technical work (Adamcik et al. 1986). This differentiation serves to create a relationship of dependence between professionals and laymen (Johnson 1993) and is thought to (re-)produce professionals' power and authority (Kerr 1997). Abstract knowledge legitimizes professionals' status and prestige because it is typically associated with science, logic, and future practical value. Of course, professionals also undertake mundane tasks, rendering their work a hybrid of conceptual and manual activities (Causer and Exworthy 1998).

Professional groups are expected to exercise high degrees of power and authority (Flynn 1998). Their power is their ability to retain jurisdiction (Abbott 1988), for example, to make decisions based upon 'internalised norms and expert knowledge' (Flynn 2002; Timmermans and Berg 2003), to influence policy, and to decide on their remuneration (Edmunds and Calnan 2001). Professional power is largely dependent upon the state's support by, for instance, defining the type and mode of services they alone can offer (Johnson 1972).

Further, professionals' power is influenced by institutional standards, codes of ethics, and behavioral norms drawn from the profession but also, to degrees, from their employing organizations (Benson et al. 2009; Johnson 1972). It can be further limited by clients' ability to organize themselves into powerful groups that set requirements, pursue their rights, and demand certain types of service (Johnson 1993).

\section{2 (Re-)Constructing Professionals through Information Technology}

The introduction of ICT in any work setting conditions changes to work practices, roles, and identities. Typically, ICT is used to gather, maintain, process, and disseminate data and information across temporal and spatial boundaries. ICT can achieve a parallel centralization and decentralization of data and information as it renders it available to anyone, anywhere (Bellamy and Taylor 1998; Bloomfield and Coombs 1992; Zuboff 1989). Further, such data can be statistically processed, ranked, compared, accumulated, and inscribed into reports, generating in that way new types of information with new uses and users (Clarke and Newman 1997; Doolin 2003; Latour 1988; Zuboff 1989). One significant way in which ICT influences professionals' work is by rendering their outputs visible (Bush et al. 2009), for example, concerning work aspects such as performance, outputs, time and date of work, and history of activities. This then renders professionals legible, in particular to 
managers (Lyon 2009). This transparency that technology provides enables constant surveillance and control, which in turn may influence reward structures and the way in which professionals do their work. For instance, Aarts et al. (2007) describe how the introduction of a computerized physician order entry (CPOE) system depersonalized healthcare professionals' collaboration and made nurses lose visibility of, and thus power over, aspects of their work.

ICT is also used to automate processes and practices (Bellamy and Taylor 1998), with implications of simplification, rule following, and tasks undertaken without human knowledge, judgment, or discretion. This promotes predictability, quantification, and centrally controlled rule-based decision making (Garson 1988). Automation is often associated with attempts to de-skill professionals and undermine their claims to professional status (Bush et al. 2009).

ICT is not always perceived as a machine that automates but may be seen as an intervention that informates work (Zuboff 1989). It does so by eliminating unnecessary activities, undertaking mundane tasks and then providing back to professionals processed information upon which they can act. In this way, ICT serves professionals in decision making and may encourage them to develop new capacities as they exploit the value of this new information (Abbott 1988). This then conditions possibilities for re-skilling by expanding the breadth and depth of their responsibilities (Zuboff 1989). In a study of a health information system in a cardiology department, Cho et al. (2008) found that ICT provided opportunities for re-skilling nurses by allowing them to download patients' images and discuss them with doctors during ward rounds.

\subsection{Pharmacists as Health Professionals}

Unlike other clinical professions, pharmacists do not specialize in specific parts of the body and do not directly intervene in the body (Barber 2005). Their work is fundamentally technological ${ }^{3}$ (Adamcik et al. 1986) in that it deals at the primary level with material objects, namely chemical components and models, delivery devices, medications, prescriptions, tokens. What distinguishes pharmacists from other healthcare professionals involved with medicines is their knowledge (abstracttion) about the ingredients of medicines, the way in which they work in the body, and their effects on it. This knowledge constitutes for Barber (2005) the "pharmaceutical gaze." Another critical feature of community pharmacists working in the high street is their hybrid role as both healthcare professionals with clinical expertise, jurisdictions, and socialservice orientation, and as business owners who look for the future viability of their business (Bush et al. 2009; Edmunds and Calnan 2001; Hibbert et al. 2002; Hughes and McCann 2003). The intrusion of the business orientation into pharmacists' profession is thought by some to condition de-skilling and standardization, leading to the rise of what Bush et al. (2009) described as the "McPharmacist."

Nonetheless, pharmacists tend to follow a scientific and rational model of thinking and acting that draws largely upon the law, and their own codes, rules, and standard operating procedures and policy guidelines (Benson et al. 2009; McDonald et al. 2010; Timmermans and Berg 2003). The profession is driven by two major values.

\footnotetext{
${ }^{3}$ Technological is defined here as the ability to use expertise and techniques in order to achieve particular objectives.
} 
The first is the value of managing medicines in a safe and reliable way (Benson et al. 2009); the second is treating the patient as a person with particular needs, values, culture, and beliefs.

In practice, however, pharmacists' work is not as rational and normative as it may look from the outside. Benson et al. (2009) present a number of examples which illustrate that pharmacists work in a non-prescriptive way in their attempt to deal professionally with complex situations. For instance, pharmacists often need to bend the rules in order to treat a patient in a "better" way or they may ration services by prioritizing some patients over others (Benson et al. 2009).

Traditionally skills and expertise of pharmacists are founded on combining the right ingredients in order to compound medicines (Adamcik et al. 1986; Eastoe 2010; Edmunds and Calnan 2001). Industrialization and increasing regulation of medicines reduced some medical risks, automated the production of many medicines, thereby increasing it, and led to the creation of new drugs with new adverse effects (Barber 2005; Bush et al. 2009; Edmunds and Calnan 2001). These changes limited the involvement of pharmacists in the production of drugs, which was now the responsibility of drug manufacturers (Bush et al. 2009), and reduced pharmacists' work to labeling and record keeping (Adamcik et al. 1986) and their role to "mere dispensers" (McDonald et al. 2010). However, in the last few years, the role of pharmacists has been reconsidered and some have argued for it to be transformed from a productfocused (Wilson et al. 2010) profession into a more clinical profession with new responsibilities for the management of prescriptions, common ailments, and long-term illness, and for the provision of medical advice on healthy lifestyles (Adamcik et al. 1986; Benson et al. 2009).

Since the 1980s, the English NHS has undertaken a number of initiatives in an attempt to re-professionalize pharmacists such as campaigns that prompt patients to turn to pharmacists for medical advice and initiatives to use their skills in order to assess patients' use and experience from medicines (McDonald et al. 2010). These initiatives, however, have not been successful in substantially strengthening the pharmacists' profession. It has been suggested that this is because pharmacists often have insufficient skills to undertake clinical responsibilities, the risk of potential conflicts with doctors, and their general weak professional power to shape public policy (Adamcik et al. 1986; Bush et al. 2009; Edmunds and Calnan 2001). In contrast to such concerns, a recent official report on hospital doctor prescribing errors ${ }^{4}$ acknowledged that almost all errors are detected and corrected by pharmacists, illustrating the high level of clinical expertise hospital pharmacists have.

\section{Research Methodology}

This research drew upon the qualitative paradigm (Creswell 1994; Maykut and Morehouse 1994) and specifically interpretivism (Klein and Myers 1999; Orlikowski and Baroudi 1991). In following an interpretivist methodology, we intended to understand through participants' oral and written accounts the meaning they attributed to

\footnotetext{
${ }^{4}$ See

http://www.gmc-uk.org/FINAL_Report_prevalence_and_causes_of_prescribing _ errors.pdf_28935150.pdf.
} 
EPS and how they projected its consequences on pharmacists' work and profession (Klein and Myers 1999).

This paper draws upon data gathered through interviews and documents. A total of 19 interviews were conducted with a number of different organizations and their representatives involved in EPS such as software suppliers for dispensing systems, community pharmacists, clinical and local EPS leads, representatives of pharmacists' associations, and representatives of Connecting for Health, the agency commissioned by the Department of Health to manage EPS. Interviews took place from June 2009 until March 2010. They were semi-structured, recorded, and when this was not possible, notes were kept. Interviews lasted 60 minutes on average and were transcribed (when possible) verbatim.

We also drew upon government documents and reports concerning the future of pharmacies, contractual arrangements, and business and workflow models. Documents and secondary studies on the profession of pharmacists, outlined above, were important in contextualizing our research and enabling us to discuss our findings in a dialogical manner that confirmed or disconfirmed our arguments (Klein and Myers 1999).

Data were analyzed by following a thematic analysis. Themes and sub-themes emerged by both our theoretical underpinnings (e.g., automation, visibility, jurisdictions, professional roles, jurisdictions) and our data (e.g., clinical orientation, temporal flexibility, patient orientation). Themes were then compared and contrasted and during this process some were merged, eliminated, further developed, and refined (Creswell 1994). Through our analysis, we constructed an analytical framework (Table 1 in Section 5) which, we hope, contributes to the more general debate about the implications of technology for professions.

\section{The Case of the Electronic Prescription Service (EPS)}

\subsection{The Introduction of EPS in English Community Pharmacy}

In England, community pharmacies are contracted by the NHS to provide pharmaceutical services in the local community (McDonald et al. 2010). Their function is influenced by a number of other organizations responsible for working with them and protecting pharmacists' interests at a national and local level (National Pharmacy Association, local pharmaceutical committees), negotiating their contractual obligetions (Pharmaceutical Services Negotiating Committee), and reimbursing them (Prescription Pricing Authority). Community pharmacies are paid to deliver NHS services and have a contract to do so, just like family doctors who work in their own businesses. Yet, their relation to the NHS is at times a contested area; one of our respondents described community pharmacists as being "in name only part of the NHS family," reflecting a view of them as independent enterprises or parts of multiple retailers rather than essentially of the health care system (Hibbert et al. 2002). However, in most cases, the majority of their income derives from fulfilling prescriptions for the NHS and their very existence is largely dependent upon NHS policy decisions which often open up critical business issues for them.

The EPS was initiated in 2003. It is a part of the National Programme for IT (NPfIT) for the NHS in England, which is delivered by the Department of Health 
agency Connecting for Health $(\mathrm{CfH})$. EPS refers to the electronic generation, transmission, and receipt of prescriptions from a prescribing authority (e.g., doctor or nurse) to a dispensing authority (e.g., community pharmacist). EPS is being rolled-out in two releases. The first (EPS1) aimed to set up and test the central infrastructure and the second (EPS2) to achieve a paperless and fully electronic transmission of prescriptions ${ }^{5}$. EPS2 also introduced new electronic functionalities: electronic cancellation, repeat dispensing of prescriptions, and pharmacy nomination. We explore the last two functions and their potential consequences for pharmacists' professional work in the following subsections.

With EPS, electronic prescriptions are sent via a central server, the Spine, which is linked to community pharmacies and general practices via the NHS's own network, N3. The Spine holds some patient demographic information and it is planned one day to hold a summary care record of each patient (Greenhalgh et al. 2010). The Spine is supported by a message handler and a broker whose role is to integrate and ensure consistency between the messages being exchanged. Prerequisite for accessing the Spine are EPS-compliant local systems and role-based access through personal user smartcards. A number of prescribing and dispensing software suppliers have been modifying their systems in line with centrally set specifications to enable the creation and exchange of electronic prescriptions. EPS has been envisioned as a project that will bring considerable benefits to pharmacists' work such as cost reduction, legible prescriptions, faster dispensing process, faster access to information, and time savings ${ }^{6}$. Most importantly for this paper, EPS opens up opportunities for (re-)shaping pharmacists' work and profession. This is discussed below.

\subsection{Changing Pharmacists' Work Practices through EPS}

Ideally, the introduction of EPS will automate aspects of the dispensing process (for example, labeling) and reduce the amount of paper that is generated. In theory, electronic prescription messages can be downloaded from the Spine and accessed and dispensed by any EPS-enabled community pharmacy across the country. Electronic prescriptions are more legible, and thus safer, and are devoid of costs associated with paper prescriptions. A paperless/paper-light process implies that pharmacists will dispense from information presented onscreen.

In the non-EPS world, the time of dispensing is defined by the patient at the point of his or her request. Under EPS, dispensing becomes temporally dispersed; it can start as soon as the prescription message is forwarded to a pharmacy. EPS2 facilitates repeat dispensing, the issuing of multiple instances of the same prescripttion for a patient to collect at the pharmacy as and when medication runs out, without the patient having to request a new prescription from the doctor each time. Through

5 EPS Release 2 Business Guidance for Initial implementers, April 2009 (http://www. connectingforhealth.nhs.uk/systemsandservices/eps/staff/guidance/release2guide.pdf).

6 "Pharmacy in England: Building on Strengths-Delivering the Future," White Paper, 2008 (Department of Health, http://www.dh.gov.uk/en/Publicationsandstatistics/Publications/ PublicationsPolicyAndGuidance/DH_083815). 
repeat dispensing, pharmacists may be able to pre-dispense and so manage better their stock and time, reduce patient waiting time, and potentially keep a patient as a repeat customer.

The prescription message populates the local computer record with patients' demographic details and the prescribed items reducing the need for manual data entry while ensuring data consistency. At the same time, it may make a pharmacy's daily functions more dependent upon complex technology and infrastructure (N3, Spine, prescribing software, etc.). In case of a technological breakdown, the pharmacy's function is likely to be brought to a halt with patients redirected to other dispensers (with possibly significant business implications).

\subsection{Changing the Values of Pharmacy Work}

Some interviewees described EPS as a means to render the relationship between doctors and pharmacists less dependent on personal acquaintance and familiarization. A representative of a pharmacists' association argued that in the pre-EPS model, the pharmacist who encountered a prescription error would, after a discussion with the doctor, perhaps by phone, dispense the correct medication and wait for the correct prescription to arrive in retrospect. This process leaves the pharmacist in a limbo both legally and financially and renders professional trust essential. In the EPS world, however, when an error is detected and changes agreed with the doctor, the pharmacist can expect the doctor to send in real time a new prescription-and indeed may not feel able to proceed until it is done. This manifests the role of technology in rendering familiarization and trust a secondary issue in computer mediated interprofessional communication. As a community pharmacist told us,

\section{At the moment I receive a prescription which clearly has an error I attach a note to that prescription, possibly write a note on it and send it back to the surgery telling the error and the reasons for the error. If you just cancel a prescription-which is effectively what you are doing by sending it back to the spine, then...they become disconnected, which actually adds another weakness to the system possibly.}

In contrast to this view, other interviewees argued that EPS could be a mechanism that fosters trust between doctors and pharmacists through the functionality of repeat dispensing. In this case, as described above, doctors rely on pharmacists to dispense the correct medication, advise on the correct dosages, pick up patient queries, and continue dispensing for the prescribed period of time. Further, a dispensing software supplier argued that the possibilities for electronic monitoring that EPS enables could potentially allow doctors to monitor whether (or not) their prescriptions have been dispensed, facilitating trust, although this functionality is not a part of EPS2.

Some participants highlighted the risks that may emerge as a prescription message gets "translated" while being transferred from a prescribing to a dispensing EPSenabled system. This may happen because different prescribing and dispensing software systems are embedded with different dictionaries-especially in relation to how medicines and their dosages are coded. As a dispensing software supplier explained, 
You don't have the proof of a piece of paper and the GP sees on his screen that he's typing out Gaviscon for instance, but what is actually sent in the message, he doesn't see that.

Some participants suggested that pharmacists will be rendered liable for undertaking these risks by using their professional judgment in order to dispense without often having complete or correct information. Professional judgment is also required with the current paper-based system, but the feeling expressed was that EPS could increase the volume of such cases.

The other new functionality that EPS2 provides is nomination, which refers to a patient's choice as to which pharmacy to use. Patients are given the opportunity to nominate any EPS2-enabled pharmacy across England from which to collect their medication. In the patient interest, and in the interest of maintaining flexibility and competition among pharmacist, nominations are expected to be easily changed. Assuming the patient does not change her nomination too frequently, nomination may allow pharmacists to accumulate data concerning patients' treatment and thus to provide more customized advice, monitor patients' health, and intervene when necessary. To a degree, such data is already held by pharmacies, but the nomination process may enable more complete information. As a representative of a dispensing software supplier said,

It's sort of like a loyalty card in the sense that, I'll always come back to you and I'll always come and get my prescriptions from you. You're tied to the patient. Therefore, you get to know who Mr Smith is.

Pharmacists, however, worry that nomination depersonalizes their relationship with patients because it makes choice less reliant on personal acquaintance and more dependent on convenience of location. Thus nomination is expected to influence the geographical distribution of pharmacies and the business potential of pharmacies in residential areas. The representatives of a pharmacy chain argued that the empowerment of patients to nominate prioritizes speedy collection of medicines over the provision of pharmacists' clinical advice. Also, some interviewees expressed concerns about the potential for "script direction," suggesting that nomination opens up the possibility for a style of competition that improves the position of large pharmacies in the market and excludes smaller pharmacies. As an interviewee said,

Pharmacies... are scared of EPS, because they think that they are going to lose control and they are going to lose business. So what pharmacists are going to do, as soon as they become EPS-enabled, is they are going to start collecting nominations from every patient that walks in their door.

Policy makers have attempted to address this risk by imposing new norms that guide prescribers and dispensers' behavior. "EPS Release 2 Business Guidance for Initial Implementers" articulates how prescribers and dispensers should behave in relation to nomination:

[Dispensing staff] shall not give or offer any gift or reward to encourage a patient to nominate them; this also includes the offering of share dividends of points, discounts and loyalty points....NHS Pharmaceutical Service Regulations 2005, prohibit pharmacists or their staff from offering inducements to encourage patients to nominate them (p. 41). 


\subsection{Changing Pharmacy Business}

EPS2 constitutes a business critical issue for most pharmacies, clearly linked to their future viability. Its potential to electronically connect pharmacists with the NHS renders pharmacists an identifiable part of it. As an official from $\mathrm{CfH}$ said,

You put in the technology, so you are making them part of the NHS family technically. They are all connected to N3 either directly or indirectly. They are all having smart cards, so that they can be uniquely identified.

Connection to the Spine requires a large financial investment in purchasing new software and a commitment for its future maintenance. This, according to a representative of a dispensing software supplier, will squeeze pharmacies' profit margins in the future. But this can be seen as part of a wider shift in the ecology; access to the Spine may potentially give pharmacists access to a summary of patients' electronic health record (the Summary Care Record) if and when this becomes widely available. The director of an independent pharmacy saw this as very important because it can inform pharmacists about patient conditions under which medicines are prescribed and allows them to judge the appropriateness of the prescription, as happens in a hospital pharmacy. Visibility of patients' records may empower pharmacists and give them more control over their work and allow them to be more patient-oriented. Apart from just viewing this information, the opportunity for feeding information into a patient record was also highlighted by some participants as an important potential advantage for pharmacists of broader EPS-enabled systems. A representative from a software supplier argued that, unlike doctors, pharmacists know the type of deregulated and over-the-counter medicines that patients take beyond what is prescribed. Feeding this information back could give a more thorough view of the patient to the doctor and lead to better consultations.

Access to patients' records may thus render the pharmacist's profession more clinically oriented. The dispensing process, we may hypothesise, would become more a back-office operation undertaken by non-professional pharmacy staff, such as accredited checking technicians, as pharmacists make better use of their skills focusing on the provision of clinical care. Indeed, as a CfH official said, the inclusion of more clinical services into pharmacists' work seems to be one vision for pharmacies in the futurex ${ }^{7}$ :

A first port of call for minor illnesses...and also as an additional service... for long term condition management.

Further, EPS could potentially give rise to new business models. Web-based pharmacies, existing and new stakeholders, such as Amazon, wholesalers or central supermarket online stores may enter into the pharmacy business in the future. These new models, which are less likely to get into the provision of clinical services, may in the future challenge pharmacists' professional identities.

7 "Pharmacy in the Future-Implementing the NHS Plan: A Programme for Pharmacy in the National Health Service," September 2000 (Department of Health, http://www.dh.gov.uk/en/Publicationsandstatistics/Publications/PublicationsPolicyAndGuida nce/DH_4005917). 
Finally, the Spine has the potential to provide the Department of Health with realtime information concerning prescribing and dispensing activity. This information, which was up until now obscured and estimated, may enable a more effecttive governing of pharmacies in the future. This is despite the fact that EPS, as a CfH official argued. has not been intentionally designed for such a purpose:

There [are] funny goings on in pharmacies and in prescribing that we don't know about. We do know about, but we've got no evidence. It's not the job of EPS to deal with that, but...there will be better quality information, quality data which people, at some point can take action and look at in detail, should they wish.

\section{Analysis}

This section discusses the possibilities that technology opens up to transform pharmacists' work and profession. Table 1 illustrates the core analytical remarks we make below.

\subsection{Screen-Level Pharmacists: Challenging the Temporal and Material Nature of Pharmacists' Work}

The case of the EPS can be seen as a manifestation of the way in which professionals can be influenced by technological advancements (Abbott 1988; McDonald et al. 2010). In summary, EPS can influence pharmacists' work in three ways. To begin with, the parallel centralization and decentralization (Bloomfield and Coombs 1992) of electronic prescriptions intends to eliminate paper and in doing so to dissociate the dispensing process from its material aspects. The strength of paper prescriptions is that they are mobile and combinable (Latour 1988); pharmacists hold a paper prescription throughout the dispensing process and check against it the medications they dispense. The mediation of technology, however, transforms them into "screenlevel" pharmacists, to borrow Bovens and Zouridis' (2002) term, who continuously need to consult a computer interface in order to conduct their daily activities.

Also, EPS might bring temporal flexibility to the dispensing process, which has been typically a temporally and spatially bound process that starts with the receipt of a paper prescription and ends with the dispensing of medications. EPS, however, transgresses temporal boundaries by allowing pharmacists to decide when they dispense (Giddens 1991; Walsham 2001). Further, EPS affords far more automation of the dispensing process by feeding complete data into pharmacists' systems, eliminating manual data entry (Bellamy and Taylor 1998).

\subsection{Clinical (Dis)orientation and Responsibilization}

EPS has the potential to generate data that informates pharmacists work (Zuboff 1989). Through the functionality of nomination, pharmacists may be able to acquire large amounts of data concerning patients' treatment and develop a better understanding of them (Benson et al. 2009). At the same time, the focus of nomination on patients' convenience may, in the long run, transform pharmacists from professionals 
into mere providers of pre-packed medications. This is likely to weaken their distinctive "pharmaceutical gaze" (Barber 2005), threaten their professional status and condition de-professionalization (Abbott 1988).

Our initial findings suggest that EPS may expand pharmacists' jurisdictions by adding further responsibilities (Abbott 1988). Electronic prescription messages may be modified while being exchanged between doctors and pharmacists. This can happen, for instance, due to possible mismatches in mapping data dictionaries. Pharmacists are then rendered responsible for interpreting the messages they receive and exercising their professional discretion, as they did in the past with handwritten and sometimes illegible prescriptions. With a high level of use of repeat dispensing, one of the main benefits claimed for EPS, pharmacists will become the primary health professional monitoring chronic diseases for periods of up to 12 months. This will often require making decisions when pharmacists have limited knowledge about the detail of a patient's case. Despite the risks that such a scenario may entail, it is likely to raise the status of the pharmacists' profession by prompting their further re-skilling (Abbott 1988).

Further, a number of participants in this research argued that EPS may provide pharmacists access to an electronic summary of a patient record. This would condition two possibilities. First, pharmacists are informed not only about what has been prescribed but also the reasons for its prescription. By knowing patients' diagnosis and treatments they also know when they should (and should not) provide specific over-the- counter medications based on possible adverse effects. They are thus able to make professional judgments and provide more clinically oriented services. One could, therefore, interpret pharmacists' possible access to a summary patient record as another government attempt to re-professionalize pharmacists by fostering the use of their clinical skills and professional judgment (Edmunds and Calnan 2001; McDonald et al. 2010). Second, and perhaps more important, pharmacists may be able to provide feedback to a patient's record. For instance, by providing information concerning over- the-counter medications patients buy (information that prescribing authorities can hardly know) pharmacists may generate information that assists clinical decision making across the prescribing and dispensing process (Doolin 2003; Latour 1988; Zuboff 1989).

\subsection{System and Interprofessional Trust through Control}

Another consequence of EPS for the pharmacy profession concerns interprofessional trust. As our research indicated, EPS has the potential to weaken personal trust by mediating between doctors and pharmacists, thus making them less interdependent. Specifically, personal and often intuitive ways of communicating are overtaken by electronic exchanges of messages between geographically distant recipients often unknown to each other. In this, EPS brings impersonality, devalues interpersonal ties, and fosters system trust (Giddens 1991).

Perhaps some interprofessional trust could be ensured through the (unintended) possibility that EPS provides for electronic monitoring. Specifically, provided that pharmacists and patients are compliant with what is prescribed, doctors may be able to monitor whether (or not) and when their prescriptions have been dispensed independently of personal acquaintance with either the patient or the pharmacist. By making pharmacists' outputs visible and legible (Lyon 2009), interprofessional trust is 
strengthened, which confirms the argument by Knights et al. (2001) that electronic monitoring technologies can substitute for the lack of trust in virtual environments.

\subsection{Professional Control, Boundaries, and Inclusion: Pharmacists as Entrepreneurs; Entrepreneurs as Pharmacists?}

Finally, Similarly, there are under-explored possibilities that EPS may provide to the government for electronic monitoring of pharmacists' outputs (Bush et al. 2009). The provision of real-time data will shed light on previously obscure aspects of the pharmacy business such as mismatches between prescribed and dispensed items. This may in turn enable auditing and decisions concerning future health budgets and pave the way to more government intervention in and thus control over pharmacists' work (Abbott 1988; Johnson 1972). Being connected to the Spine is also likely to bring about two consequences for pharmacists' professionalization. By allowing pharmacists' access to NHS-related information, such as patients' demographic information and diagnoses and treatments, and by making them identifiable to and tractable by the NHS, it also renders them, to use a participant's words, a part of the NHS family. This indicates one role that technology-as a boundary creating mechanism-might play in professionalizing pharmacists through deeper inclusion into the NHS (Adamcik et al. 1986). Access to patient data may also create more business opportunities for pharmacists by allowing them to target patient groups effectively and provide customized services.

At the same time, the possibilities for inclusion that EPS provides may shift the boundaries of pharmacists' profession in other ways, for example, by enabling new business models to emerge such as Internet-based pharmacies using the Internet,

Table 1. The Implication of ICT in Pharmacists' Profession

\begin{tabular}{|l|l|l|}
\hline \multicolumn{1}{|c|}{ ICT possibilities } & \multicolumn{1}{|c|}{ Aspects of Profession } & \multicolumn{1}{c|}{ Features of Change } \\
\hline Centralization/Decentrali- & Work practices & Immaterial aspects \\
\cline { 3 - 3 } zation of information & & Temporal flexibility \\
\cline { 3 - 3 } & & Elimination of manual tasks \\
\hline Automation & Roles & Screen-level pharmacists \\
\hline Generation of information & Values & $\begin{array}{l}\text { Informatization and patient } \\
\text { orientation }\end{array}$ \\
\cline { 2 - 3 } & Roles & Delivery orientation \\
\cline { 2 - 3 } & Jurisdictions & Responsibilization \\
\hline Transformation & Jurisdictions & Clinical orientation \\
\hline Computer Mediated & Values & System trust and impersonality \\
\hline Communication & & Governing \\
\cline { 3 - 3 } Visibility & Control and Power & Interprofessional trust/control \\
\hline Connectivity & & Inclusion \\
\cline { 3 - 3 } & Professional boundaries & New business models \\
\hline
\end{tabular}


telephone, and post. Interviewees underlined the risks that new business models may bring for pharmacists. They mentioned the potential for illicit competition and patient direction and the diffusion of a business logic that would corrode pharmacists' professionalism by redirecting it toward a profit-driven delivery model. This aligns with a number of studies that emphasize the entrepreneurial character of many public service professionals (Clarke and Newman 1997; Du Gay 2000) and suggests that EPS could be perceived as an intensification of entrepreneurialism in healthcare-a feature of the recently elected government's health policy. Such risks are historically counter-balanced by governmental interventions that protect and maintain pharmacists' professional status (Johnson 1972), but should we count on it?

\section{Conclusion}

The paper discusses the possibilities that technology opens up to transform the pharmacist profession in the future. We have argued that technology has the potential to centralize and decentralize, automate and informate practices and processes, generate new information, mediate communication, and render outputs visible. The six aspects of pharmacists' work we consider, work practices, values, roles, jurisdictions, power, and boundaries, are all open to adjustment. By accommodating multiple interpretations, we present different and often opposing narratives of the future of the pharmacist profession (Klein and Myers 1999). One possible interpretation is that pharmacists' work will become an immaterial, temporally dispersed computerized process, and that pharmacists will be transformed into screen-level professionals as providers of accurately specified medicines. But EPS could potentially bring about more fundamental changes that run counter. For example, pharmacists' values may change to become more patient-oriented as they develop more clinical roles. And system trust may be a powerful substitute for interpersonal trust as EPS strengthens their profession by expanding their responsibilities, and thus their jurisdictions. Further, EPS could provide nuanced forms of electronic control that can enable better monitoring and management of dispensing outputs and foster interprofessional trust.

These changes, presented in Table 1, constitute the framework we have developed to project and analyze the implications of technology for professionals. We provided a critical analysis of these implications but did not make a prediction about how these will shape professionals in the future. This is not just because EPS has not been nationally rolled-out but primarily because changes in professions and the way that professionalization is enacted are long-term, multidimensional- evolving in parallel with political, technological, and financial changes-and thus open to interpretation. They can hardly be known in advance.

\section{Acknowledgments}

The authors would like to thank the interviewees that participated in this study, James Davies, Ph.D. candidate at the School of Pharmacy, University of London, and the research team for their comments in an early draft of the paper.

The Evaluation of the Electronic Prescription Service in Primary Care is a collaboration between The School of Pharmacy, University of London, The London School of Economics and Political Science, and The University of Nottingham, under 
the leadership of Professors N. Barber, A. Avery, and R. Elliott, and Dr. T. Cornford. It is funded by the Connecting for Health Evaluation Programme.

This report is independent research commissioned by the National Institute for Health Research. The views expressed in this publication are those of the author(s) and not necessarily those of the NHS, the National Institute for Health Research, or the Department of Health.

\section{References}

Aarts, J., Ash, J., Berg, M.: Extending the Understanding of Computerized Physician Order Entry: Implications for Professional Collaboration, Workflow and Quality of Care. I. J. of Medical Informatics 76, S4-S13 (2007)

Abbott, A.: The System of Professions: An Essay on the Division of Expert Labor, 1st edn. University of Chicago Press, Chicago (1988)

Adamcik, B.A., Ransford, H.E., Oppenheimer, P.R., Brown, J.F., Eagan, P.A., Weissman, F.G.: New Clinical Roles for Pharmacists: A Study of Role Expansion. Social Science \& Medicine 33(11), 1187-1200 (1986)

Barber, N.: The Pharmaceutical Gaze-The Defining Feature of Pharmacy. The Pharmaceutical Journal 275, 78 (2005)

Bates, D.W., Gawande, A.A.: Improving Safety with Information Technology. The New England J. of Medicine 348(25), 2526-2534 (2003)

Bellamy, C., Taylor, J.: Governing in the Information Age. Open University Press, New York (1998)

Benson, A., Cribb, A., Barber, N.: Understanding Pharmacists' Values: A Qualitative Study of Ideals and Dilemmas in UK Pharmacy Practice. Social Science \& Medicine 68(12), 2223-2230 (2009)

Berg, M.: Rationalizing Medical Work: Decision-Support Techniques and Medical Practices. MIT Press, Cambridge (1997)

Bloomfeld, B.P., Coombs, R.: Information Technology, Control and Power: The Centralization and Decentralization Debate Revisited. J. of Management Studies 29(4), 459 (1992)

Bovens, M., Zouridis, S.: From Street-Level to System-Level Bureaucracies: How Information and Communication Technology is Transforming Administrative Discretion and Constitutional Control. PAR 62(2), 174-184 (2002)

Bush, J., Langley, C., Wilson, K.: The Corporatization of Community Pharmacy: Implications for Service Provision, the Public Health Function, and Pharmacy's Claims to Professional Status in the United Kingdom. Research in Social and Administrative Pharmacy 5(4), 305-318 (2009)

Causer, G., Exworthy, M.: Professionals as Managers across the Public Sector. In: Professionals and the New Managerialism in the Public Sector. Open University Press, Stony Stratford (1998)

Chiasson, M., Davidson, E.: Pushing the Contextual Envelope: Developing and Diffusing IS Theory for Health Information Systems Research. Information and Organization 14(3), 155-188 (2004)

Cho, S., Mathiassen, L., Nilsson, A.: Contextual Dynamics During Health Information Systems Implementation: An Event-Based Actor-Network Approach. European J. of Information Systems 17, 614-630 (2008)

Clarke, J., Newman, P.J.E.: The Managerial State: Power, Politics and Ideology in the Remaking of Social Welfare. Sage Publications Ltd., London (1997) 
Creswell, D.J.W.: Research Design: Qualitative and Quantitative Approaches, annotated edition. Sage Publications, Inc., Thousand Oaks (1994)

Doolin, B.: Narratives of Change: Discourse, Technology and Organization. Organization 10(4), 751-770 (2003)

Du Gay, P.: Enterprise and its Futures: A Response to Fournier and Grey. Organization 7(1), $165-183$ (2000)

Eastoe, J.: Victorian Pharmacy Remedies and Recipes. Pavilion, Philadelphia (2010)

Edmunds, J., Calnan, M.: The Re-professionalization of Community Pharmacy? An Exploration of Attitudes to Extended Roles for Community Pharmacists Amongst Pharmacists and General Practitioners in the United Kingdom. Social Science and Medicine 53, 943-955 (2001)

Flynn, R.: Managerialism, Professionalism and Quasi-Markets. In: Professionals and the New Managerialism in the Public Sector. Open University Press, New York (1998)

Flynn, R.: Clinical Governance and Governmentality. Health, Risk \& Society 4(2), 155 (2002)

Garson, B.: The Electronic Sweatshop: How Computers Are Turning the Office of the Future into the Factory of the Past. Simon \& Schuster, New York (1988)

Giddens, A.: The Consequences of Modernity. Stanford University Press, Stanford (1991)

Greenhalgh, T., Stramer, K., Bratan, T., Byrne, E., Russell, J., Hinder, S., Potts, H.: The Devil's in the Detail: Final Report of the Independent Evaluation of the Summary Care Record and Health Space Programmes. University College London, London (2010)

Hibbert, D., Bissell, P., Ward, P.R.: Consumerism and Professional Work in the Community Pharmacy. Sociology of Health \& Illness 24(1), 46-65 (2002)

Hodgson, D.: Putting on a Professional Performance: Performativity, Subversion and Project Management. Organization 12(1), 51-68 (2005)

Hughes, C., McCann, S.: Perceived Interprofessional Barriers between Community Pharmacists and General Practitioners: A Qualitative Assessment. British J. of General Practice 53(493), 600-606 (2003)

Johnson, T.: Expertise and the State. In: Foucault's New Domains, Routledge, London (1993)

Johnson, T.: Professions and Power, 1st edn. Palgrave Macmillan, Basingstoke (1972)

Kerr, A., Cunningham-Burley, S., Amos, A.: The New Genetics: Professionals' Discursive Boundaries. Sociological Review 45(2), 279-303 (1997)

Kirkpatrick, I., Ackroyd, S.: Archetype Theory and the Changing Professional Organization: A Critique and Alternative. Organization 10(4), 731-750 (2003)

Klein, H.K., Myers, M.D.: A Set of Principles for Conducting and Evaluating Interpretive Field Studies in Information Systems. MIS Quarterly 23(1), 67-93 (1999)

Knights, D., Noble, F., Vurdubakis, T., Willmott, H.: Chasing Shadows: Control, Virtuality and the Production of Trust. Organization Studies 22(2), 311-336 (2001)

Latour, B.: Science in Action: How to Follow Scientists and Engineers Through Society. Harvard University Press, Cambridge (1988)

Lyon, D.: Identifying Citizens: ID Cards as Surveillance. Polity Press, Cambridge (2009)

Maykut, P., Morehouse, R.: Beginning Qualitative Research: A Philosophical and Practical Guide, 1st edn. Routledge, London (1994)

McDonald, R., Cheraghi-Sohi, S., Sanders, C., Ashcroft, D.: Professional Status in a Changing World: The Case of Medicines Use Reviews in English Community Pharmacy. Social Science \& Medicine 71(3), 451-458 (2010)

Orlikowski, W.J., Baroudi, J.J.: Studying Information Technology in Organizations: Research Approaches and Assumptions. Information Systems Research 2(1), 1-28 (1991)

Perkin, H.: The Rise of Professional Society: England Since 1880, 2nd edn. Routledge, London (2002) 
Timmermans, S., Berg, M.: The Gold Standard: The Challenges of Evidence-Based Medicine and Standardization in Health Care. Temple University Press, Philadelphia (2003)

Walsham, G.: Making a World of Difference: IT in a Global Context, 1st edn. Wiley, Chichester (2001)

Wilson, S., Tordoff, A., Beckett, G.: Pharmacy Professionalism: A Systematic Analysis of Contemporary Literature (1998-2009). Pharmacy Education 10(1), 27-31 (2010)

Zuboff, S.: In the Age of the Smart Machine: The Future of Work and Power. Basic Books, New York (1989)

\section{About the Authors}

Dimitra Petrakaki is a postdoctoral research officer at the London School of Economics and Political Science. Her research focuses on the relation between information technology, power, and knowledge, and its implication for organizational change. She is currently conducting research into the introduction of electronic health records and electronic transfer of prescriptions in the English NHS. She can be reached atd.petrakaki@1se.ac.uk

Tony Cornford is a senior lecturer in Information Systems at the London School of Economics and Political Science. He is interested in IT in health care, IS implementation, the open source software process, and socio-technical and sociocognitive approaches to IS. His latest work has been in the area of electronic prescribing, electronic health records, and electronic transfer of prescriptions in the English NHS. He can be reached at t.cornford@1se.ac.uk

Ralph Hibberd is a research fellow at the School of Pharmacy, University London. His research focuses on safety and usability of complex (information) systems and on users' sense making and behavior. He is currently working as a project coordinator and researcher into the electronic yransfer of prescriptions initiative of the English NHS. He can be reached at ralph.hibberd@pharmacy.ac.uk

Valentina Lichtner is a postdoctoral research officer at the London School of Economics and Political Science. She is interested in adoption and adaptation of IT in healthcare, evaluation of systems, identity, and identification technology, humancomputer interaction, and patient safety. She is currently conducting research into the introduction of electronic health records and electronic transfer of prescriptions in the English NHS. She can be reached at v.lichtner@lse.ac.uk

Nick Barber is Professor of the Practice of Pharmacy at the School of Pharmacy, University London. He held positions at the London School of Economics and Political Science and at Harvard Medical School. His research focuses on medication errors, technology evaluation, adherence, and the philosophy of prescribing and of pharmacy. He is a principal investigator for two research projects that evaluate the National Care Record Service and the Electronic Prescription Service in the English NHS. He can be reached at n.barber@ pharmacy.ac.uk. 